\section{Food-Borne Viruses: Progress and Challenges}

\author{
Marion P.G. Koopmans, \\ Dean O. Cliver, and Albert Bosch, \\ editors
}

American Society for Microbiology Press, Washington, DC, USA, 2008 ISBN: 978-1-55581-464-9

Pages: 245; Price: US \$99.95

One question that is well known to persons working with food virology, and especially noroviruses, is "How important are these viruses, actually?" Frequently you feel somewhat uneasy when you start to reply, talking about the "trivial illness" of gastroenteritis, continuing on to the economic impact caused by the huge number of cases, and finally ending up admitting that you really do not know the answer. This book does not provide an answer to this difficult question either, but it does give you, among other things, an introduction to the pitfalls in trying to "estimate the burden of an underreported disease." One conclusion is that we probably underestimate its importance.

The book consists of 10 chapters written by persons well known to food virologists as experts in their fields. It is well organized, well written, and presents the history of foodborne viruses, the state of the art, and a glance into the future. The history of food virology is given by Dean O. Cliver, one of the pioneers in this area, who spices up his contribution by sharing interesting personal experiences with the reader. Most of the focus in the book is, naturally, directed toward norovirus and hepatitis A virus. These viruses are covered by up-to-date presentations on molecular biology, clinical disease and diagnostics, pathogenesis and immunity, epidemiology, and detection in food matrixes. Recommendations are also given about which foods should be tested and under which circumstanc- es. Although protocols are not presented, many references are listed.

The molecular revolution has improved the detection of viruses that are impossible or difficult to propagate in cell culture, such as norovirus and hepatitis A virus, and reverse transcription-PCR has become the standard method for virus detection in food. However, sensitive detection methods are still lacking. This is one of the recurrent topics in the book because it affects outbreak investigation, risk assessment, and risk management.

The need for standardization for virus detection in food is stated, as is the proper use of controls. Nobody will argue against detection of falsenegative and false-positive results, but some thoughts on the cost-benefit aspects regarding accurate quantification of virus genomes in foods would have been interesting.

The book provides a broad overview of the present situation and gives a good introduction to the topic. Factors that may contribute to the emergence of new viral diseases are also discussed, including demographic and pathogen-related changes. This is interesting reading because virus families and viral evolution are discussed within the context of foodborne transmission. The editors encourage the reader to enjoy the book, and, most of the time, I did.

\section{Mette Myrmel}

Author affiliation: Norwegian School of Veterinary Science, Oslo, Norway

DOI: 10.3201/eid1411.080819

Address for correspondence: Mette Myrmel, Norwegian School of Veterinary Science, Ullevaalsveien 72, Oslo 0033, Norway; email: mette.myrmel@veths.no

\section{Searching Eyes: Privacy, the State, and Disease Surveillance in America}

\author{
Amy L. Fairchild, Ronald Bayer, \\ and James Colgrove \\ University of California Press, \\ Berkeley, California, USA, 2007 \\ ISBN-10: 978-0-520-25202-8 \\ ISBN-13: 978-0-520-25325-4 \\ Pages: 342; Price: US \$19.95 (soft \\ cover)
}

Searching Eyes is a history of privacy, a value central to the American democratic way of life, and disease surveillance, a core activity critical to the public health mission of intervening as appropriate to protect the populace from preventable causes of illness and death. Public health surveillance is framed as a social practice that is embedded within particular contexts rather than as a purely technical undertaking insulated from politics, law, economics, ethics, and societal forces. The authors cite encounters with tuberculosis (TB), syphilis, HIV/AIDS, and immunization registry efforts to illustrate the pervasive tension in disease surveillance activities that has existed between privacy and the welfare of society since the inception of surveillance in the 19th century.

Although public health officials take for granted the long-established disease surveillance system that enables them to monitor the public's health, such practices are not viewed as positively by the populace who contest the feared intrusion into what is perceived as an American's right to privacy. Even the medical community, our strongest ally in public health activities, has feared the intrusion and encroachment of the doctor-patient relationship. The well-publicized AIDS struggle in the early 1980s captured our attention as we strived to respond to the political and ethical ques- 
tions that, up until that time, had only received an episodic focus.

One drawback of the book is that the authors cover a wide gamut of topics. Consequently, disease-specific topics are presented without adequately providing the necessary background on the disease entity to the reader. Not all readers may fully understand the necessary disease-specific background that would make the discussions of public health intervention understandable. For instance, the chapter on TB presents a history of the disease from the turn of the 20th century. But if the reader were unaware of the public health threat posed by the undiagnosed or nonadherent TB patient, the reader would understandably question the authority of public health practitioners to occasionally take extraordinary steps to ensure that infection is not transmitted within the community.

Even without a comprehensive background on specific diseases, this book will interest a wide audience, not only public health practitioners but the medical and legal community with whom we partner. Searching Eye tackles a topic that deserves more of our respective attention, for as noted by the authors, "The vitality of democratic communities necessitates an ongoing effort to negotiate and renegotiate the boundaries between privacy, society's limiting principle, and public health, which at its best has sought to expand the role of government as a guardian against disease and suffering." I congratulate the authors on their wellresearched and thorough discourse on this core public health activity.

\section{Kathleen F. Gensheimer}

Author affiliation: Maine Department of Health and Human Services, Augusta, Maine, USA

DOI: 10.3201/eid1411.081034

Address for correspondence: Kathleen F. Gensheimer, Maine Department of Health and Human Services, State House \#11, Augusta, ME 04333, USA; email: kathleen.f.gensheimer@ maine.gov

\section{Emerging Pests and Vector-borne Diseases in Europe}

Willem Takken and Bart G.J. Knols, editors

Wageningen Academic Publishers, Wageningen, the Netherlands, 2007 ISBN-10: 9086860532

ISBN-13: 978-90-8686-053-1

Pages: 500; Price: US \$141.00

Today's hot topic is the risk of introducing new vector-borne diseases and harmful ectoparasites into Europe, or of the geographic extension of existing ones. The recent outbreaks of bluetongue virus infection in northwestern Europe and of chikungunya infection in Italy are real reminders of the vulnerability of this ill-prepared continent, where the idea prevails that these things cannot happen there but are merely problems that occur on other continents.

This book is the first volume of a new series, "Ecology and Control of Vector-Borne Diseases," written by more than 70 European scientists who are recognized experts in their specific fields. The cover text states that in 24 chapters "this book provides examples of the most likely pests and diseases affecting man and animals in Europe, with emphasis on ecological factors favoring these diseases and methods for prevention and intervention." Indeed, the raised expectations are largely fulfilled.

The book is divided into 6 sections preceded by an appealing introductory chapter-Alarm Bells Ringing: More of the Same, and New and Novel Diseases and Pests - and followed by a poignant epilogue, which summarizes the different problem areas discussed in the book as well as concise actions proposed to reduce the threats.

In the first section, pertinent questions are answered on the possible return of malaria in Europe and on the problem of leishmaniasis in southern Europe. Avian malaria, a rather un- known but interesting paradigm, is discussed as well. In the second section, different arboviruses such as bluetongue, West Nile, chikungunya, and dengue are discussed in addition to the rather unknown Usutu virus. Readers can download the well-written chapter on chikungunya and dengue in southern Europe from www.wageningenacademic.com. The third section gives an overview on the current problems of tick-borne encephalitis and Lyme disease in Europe; discussion is limited to the Baltic States and the Netherlands, respectively. The fourth section discusses strategies on the following emerging arthropod pests and problems: psoroptic mang, the establishment and spread of the Aedes albopictus mosquito in Europe, bed bugs, houseflies, head lice, and Culicoides midges. The authors highlight the most recent information on pest control with an emphasis on tools other than classic chemical control to manage these infestations because these pests are likely to escape these classic chemical tools in the future. In the fifth section, Surveillance, Protection and Control, the authors discuss monitoring systems for adult insect pests and disease vectors, personal protection against European disease vectors, and mosquito control in Europe. The last section, Nature Conservation, Wildlife Management and Human Activities as Drivers, covers subjects such as changes in global scale land use and its implications for nature conservation and emerging vector-borne diseases, wildlife and the risk of vectorborne viral diseases, and invasions of vector-borne diseases driven by transportation and climate change.

Throughout the book, the role of the different factors that drive the changing epidemiology of diseases and pests is described in a well-balanced manner. This changing epidemiology is recognized as a possible consequence of the complex interplay of factors such as climate change (whether or not it is anthropogenic), 